\title{
Patient Teenagers? A Comparison of the Sexual Behavior of Virginity Pledgers and Matched Nonpledgers
}

\author{
Janet Elise Rosenbaum, PhD, AM \\ Health Policy PhD Program, Harvard University, Cambridge, Massachusetts; Department of \\ Population, Family, and Reproductive Health, Johns Hopkins Bloomberg School of Public Health, \\ Johns Hopkins University, Baltimore, Maryland
}

\begin{abstract}
OBJECTIVE-The US government spends more than $\$ 200$ million annually on abstinencepromotion programs, including virginity pledges. This study compares the sexual activity of adolescent virginity pledgers with matched nonpledgers by using more robust methods than past research.
\end{abstract}

\begin{abstract}
SUBJECTS AND METHODS-The subjects for this study were National Longitudinal Study of Adolescent Health respondents, a nationally representative sample of middle and high school students who, when surveyed in 1995, had never had sex or taken a virginity pledge and who were $>15$ years of age $(n=3440)$. Adolescents who reported taking a virginity pledge on the 1996 survey $(n=289)$ were matched with nonpledgers $(n=645)$ by using exact and nearest-neighbor matching within propensity score calipers on factors including prepledge religiosity and attitudes toward sex and birth control. Pledgers and matched nonpledgers were compared 5 years after the pledge on self-reported sexual behaviors and positive test results for Chlamydia trachomatis, Neisseria gonorrhoeae, and Trichomonas vaginalis, and safe sex outside of marriage by use of birth control and condoms in the past year and at last sex.
\end{abstract}

RESULTS-Five years after the pledge, $82 \%$ of pledgers denied having ever pledged. Pledgers and matched nonpledgers did not differ in premarital sex, sexually transmitted diseases, and anal and oral sex variables. Pledgers had 0.1 fewer past-year partners but did not differ in lifetime sexual partners and age of first sex. Fewer pledgers than matched nonpledgers used birth control and condoms in the past year and birth control at last sex.

CONCLUSIONS-The sexual behavior of virginity pledgers does not differ from that of closely matched nonpledgers, and pledgers are less likely to protect themselves from pregnancy and disease before marriage. Virginity pledges may not affect sexual behavior but may decrease the likelihood of taking precautions during sex. Clinicians should provide birth control information to all adolescents, especially virginity pledgers.

Copyright (C 2009 by the American Academy of Pediatrics

Address correspondence to Janet Elise Rosenbaum, PhD, Department of Population, Family, and Reproductive Health, Johns Hopkins Bloomberg School of Public Health, 615 N Wolfe St., 4th Floor, Baltimore, MD 21205. E-mail: jerosenb@jhsph.edu.

The author has indicated she has no financial relationships relevant to this article to disclose.

This research was approved by the Harvard University Human Subjects Board. Dr Rosenbaum conceived the project, analyzed the data, interpreted the results, and wrote the article.

This article was presented in part at an Association for Public Policy Analysis and Management meeting (poster), November 7, 2008, Los Angeles, CA; an American Public Health Association meeting, October 28, 2008, San Diego, CA; the R User Conference, August 12, 2008, Dortmund, Germany; Joint Statistical meetings, August 3, 2008, Denver, CO; George Washington University, June 25, 2008, Washington, DC; the International Conference on Health Policy Research, January 17, 2008, Philadelphia, PA; and a Johns Hopkins STD Center research seminar, December 19, 2007, Baltimore, MD. 


\section{Keywords}

sexual abstinence; sexual behavior; sexual partners; contraception; adolescent; religion and sex; Christianity; nonparametric statistics; matched-pair analysis

\section{What's Known on This Subject}

Two studies have found, by using regression, that virginity pledges delay sex, but regression cannot correct for large preexisting differences between pledgers and nonpledgers.

\section{What This Study Adds}

We used a more robust method than regression to compare virginity pledgers with similar nonpledgers and found virtually no difference in sexual behavior or STDs and much less use of condoms.

Reducing early adolescent sexual initiation is an important public health objective. Early sexual initiation is associated with sexual risk-taking, pregnancy, and sexually transmitted diseases (STDs). ${ }^{1,2}$ Well-designed sex education programs that teach both abstinence and contraception can delay sexual initiation ${ }^{3,4}$ and prevent pregnancy, STDs, and risky sexual behavior. ${ }^{1,3-5}$ Abstinence-only sex education (AOSE) programs are defined by statute as having the "exclusive purpose [of] teaching the social, psychological, and health gains [of] abstaining from sexual activity." behavior in either the congressionally mandated randomized experiment ${ }^{7}$ or the systematic review of well-designed AOSE studies, ${ }^{8}$ but AOSE funding has increased dramatically, from $\$ 73$ million in 2001 to $\$ 204$ million in 2008. 6 ,9

A sexual abstinence or "virginity" pledge is an oral or written promise to refrain from sexual activity, usually until marriage, administered after a multi- or single-session curriculum in religious youth groups, parochial and public schools, or large group events. The virginity pledge and 6-hour curriculum were created in 1993 by an evangelical Christian organization. The idea was subsequently spread by other Protestant and Catholic groups, which created pledges for their own AOSE programs for both religious and secular adolescents. By 1995, $13 \%$ of American adolescents reported having taken a virginity pledge. ${ }^{10}$ Virginity pledges are also now used to measure AOSE program effectiveness, which the US government considers successful if they produce many virginity pledgers, irrespective of participants' sexual behavior. ${ }^{6,11}$ This standard raises the question of whether virginity pledgers are less sexually active than comparable adolescents.

Studies using regression models have shown that virginity pledgers in a nationally representative sample were less likely to become sexually active than non-pledgers 1 and 5 years after the pledge, ${ }^{10,12,13}$ equally likely to have STDs 5 years after the pledge, ${ }^{10,13}$ and less likely to use contraception than nonpledgers. ${ }^{12}$

A California study showed greater sexual abstinence among adolescents who made a personal resolution not to have sex but not among formal virginity pledgers. ${ }^{14}$ These studies were critiqued for comparing pledgers with dissimilar nonpledgers. ${ }^{11}$

Regression models in past studies compared pledgers with the universe of nonpledgers despite dissimilarities that regression may be unable to correct. ${ }^{15-17}$ One year before pledging, pledgers are more religious, less sexually experienced, and hold more negative attitudes about sex and 
birth control than adolescents who do not go on to take a virginity pledge. ${ }^{10,12}$ Religious adolescents delay sexual initiation, ${ }^{18-21}$ so virginity pledgers' prepledge religiosity could induce abstinence without the pledge.

Given regression's recognized limitations, ${ }^{15-17}$ this article is distinctive in using matched sampling methods ${ }^{22-26}$ to compare the sexual and contraceptive behavior of virginity pledgers with similar nonpledgers in a national longitudinal study 5 years after a pledge is made.

\section{METHODS}

Matched sampling is a nonparametric method for assessing program outcomes by comparing a program group with similar nonprogram respondents. ${ }^{22-24} \mathrm{We}$ created a group of nonpledgers as similar as possible to pledgers on all prepledge factors that may influence sexual behavior, so outcome differences between pledgers and matched non-pledgers cannot be attributed to preexisting differences. Past studies compared self-selected virginity pledgers with the general population and attempted to adjust for the vast prepledge differences by using regression models.

Both matching and regression yield associative rather than causal inference, but matching creates more valid comparisons and results for 3 reasons. First, regression models rely on dubious parametric assumptions and cannot adjust, even on average, for large differences between program and nonprogram groups. ${ }^{15,16,24,25}$

Second, matching computes outcome differences only once, after verification that the matched nonprogram group is similar to the program group. This separation ensures that the model is selected independently of the study's results, in contrast to regression, with which it is impossible to verify model correctness without seeing the results. Third, matching allows adjustment for many more variables than does regression. In this study, I controlled for 112 variables, which would be problematic in a regression with 289 pledgers. For these reasons, matched sampling has been advocated for studies in medicine and public health ${ }^{27-29}$ and is used increasingly often in the medical literature. ${ }^{30-34}$

\section{Data}

Data are a subsample of the National Longitudinal Study of Adolescent Health (Add Health), ${ }^{*}$ a nationally representative sample of grade 7 to 12 students interviewed in 3 waves (in 1995 [wave 1], 1996 [wave 2], and 2001 [wave 3]), as described elsewhere. ${ }^{35,36}$ The subsample comprises respondents who had not at wave 1 taken a virginity pledge or been sexually active, were $>15$ years of age, and participated in all 3 waves $(n=3440)$.

Respondents $<15$ years of age were not asked about sex and birth control attitudes, which likely influence both virginity pledge and sexual activity, so they were excluded from analysis.

Attrition in the subsample was $12 \%$ between waves 1 and 2 and $26 \%$ between waves 2 and 3, similar to that in the larger sample. Survey weights developed for the entire sample are inadequate for a constrained sub-sample and were not used.

\footnotetext{
*Add Health is a program project designed by J. Richard Udry, Peter S. Bearman, and Kathleen Mullan Harris, and funded by National Institute of Child Health and Human Development grant P01-HD31921, with cooperative funding from 17 other agencies. Special acknowledgment is due to Ronald R. Rindfuss and Barbara Entwisle for assistance in the original design. Persons interested in obtaining data files from Add Health should contact Add Health, Carolina Population Center, 123 W Franklin St, Chapel Hill, NC 27516-2524 (www.cpc.unc.edu/addhealth/contract.html).
} 


\section{Variables}

Virginity-pledge status is the wave 2 answer to "Have you ever signed a pledge to abstain from sex until marriage?" Predictors of virginity pledge were measured at wave 1, 1 year before the pledge, and so cannot be attributed to the pledge as wave 2 factors could be. Factors for exact and nearest-neighbor caliper matching were selected from 128 potential predictors derived from past-pledge literature ${ }^{10,12-14}$ and the National Institute of Mental Health integrated health behavior model ${ }^{37}: 16$ composite variables, their 85 component survey items, and 27 other items. (Major categories and example items are listed in Table 1; the full list is available in the Appendix.)

Outcome variables measure sexual behavior and STD diagnosis and prevention 5 years after the pledge, when the sample was at median 22 years of age (interquartile range: $20-23$ years). STDs were diagnosed from urine-test results; all other outcomes were self-reported.

Respondents' use of STD- and pregnancy-prevention methods before marriage was measured by reported birth control and condom use in the past 12 months and at last sex and was coded as missing for married respondents.

Outcome differences were biased toward showing an effect of the pledge for 2 reasons: the pledge is an intermediate outcome of an unobserved abstinence intervention, which would be the treatment variable in an experiment; and pledgers may be less likely to report sexual activity than nonpledgers. ${ }^{38}$

\section{Matched Sampling}

Matched sampling attempts to create a group of nonpledgers with prepledge characteristics similar to pledgers, as would be true in a randomized experiment. ${ }^{17,22-24}$ Ideally, exact duplicates of every pledger could be found among the nonpledgers. ${ }^{31}$ Instead, matching creates a comparison group with a similar distribution of preprogram factors, which is thus the primary criterion for assessing match quality. ${ }^{23,24,26}$ There are not yet standardized guidelines for choosing a matching procedure, ${ }^{23,27}$ and matching methods yield similar results in simulation, ${ }^{23}$ but nearest-neighbor caliper matching is generally recommended. ${ }^{23}$ Exact matching can be combined with any method to make respondents identical on factors that might otherwise cause large differences, similar to blocking in randomized experiments. ${ }^{23,25} \mathrm{~A}$ matching method's appropriateness is gauged postfacto by the balance achieved, so any method and choice of matching factors that result in balanced groups is considered appropriate. ${ }^{23,24}$

This study used 2 types of matching: exact matching and 3:1 nearest-neighbor matching within propensity score calipers with replacement, using the R package MatchIt. ${ }^{25,39}$ The 2 exact matching factors were anticipating feeling guilty if they had sex and weekly attendance at church and/or religious youth group, conceptually distinct items with the largest mean prematching differences between pledgers and nonpledgers (Table 1). Propensity scores are the estimated probability of taking a virginity pledge calculated from a stepwise logistic regression.

Nearest-neighbor matching within propensity score calipers locates the 3 nonpledgers "closest" to each pledger, preferentially within calipers of $0.25 \mathrm{SDs}$ in propensity score. The Mahalanobis metric measures the correlation-adjusted distance between respondents on the basis of respondents' values of continuous variables. The variables used in the distance measure are derived through trial and error by including and excluding variables until balance is achieved. Balance was achieved by using 4 composite variables in the metric: religious involvement, negative attitudes about birth control, parent religiosity, and pubertal development. 
Match adequacy is determined by "balance," the similarity of the covariate distributions of pledge and nonpledge groups. The $t$ test is commonly used to assess balance at mean, but there is not yet consensus on the best way to assess balance across the entire distribution. ${ }^{25,26,30}$ This study assessed balance by using the $t$ test and visual inspection of empirical quantilequantile plots. ${ }^{26,30}$

Once balance was achieved, the outcomes of virginity pledgers and matched nonpledgers were compared with a $t$ test. Cohen's effect size $d$, a measure independent of sample size, was calculated for significant differences: 0.2 is classified as small, 0.5 as medium. ${ }^{40}$

For illustrative comparison of differences between our restricted group and adolescents nationwide, survey-adjusted means of wave 3 outcomes were computed in Stata (Stata Corp, College Station, TX).

\section{RESULTS}

In ordinary regression, virginity pledgers would be compared with all nonpledgers, but these groups differed 1 year before taking the pledge. Comparing the 289 pledgers and 3151 nonpledgers at wave 1 before matching, pledgers were less sexually experienced and expected more negative and fewer positive psychosocial effects of sex and birth control use, with lower birth control efficacy and knowledge. Pledgers had greater levels of religious belief, involvement, Born Again affiliation, more religious parents, and fewer substance-using friends and were more likely to expect marriage before age 25 . Pledgers also were disproportionately female, Asian, with foreign-born parents, and had lower Peabody vocabulary test scores (Table 1 and Appendix). Survey design parameters (region, cluster, and weight) were attempted as covariates in the propensity score model but were not significant.

The 3:1 matching with replacement matched 645 nonpledgers to the 289 pledgers. Matched pledgers and nonpledgers did not differ on average in propensity score, 16 composite variables and their 85 component items, and 27 other variables (Table 1 and Appendix). By simple chance, $5 \%$ of comparisons on average will be significant at the .05 level; 0 of the 128 comparisons are significant, so balance is better than expected by chance.

Turning to outcomes, 5 years after the pledge, $81.9 \%$ (confidence limits [CLs]: 76.2\%, 87.6\%) of virginity pledgers claimed to have never pledged. Virginity pledgers and matched nonpledgers did not differ in 12 of 14 sexual behaviors, 3 of 3 STD test results, and 4 of 4 marriage-related outcomes (Table 2). Pledgers reported an average of 1.09 past-year vaginal sex partners, 0.11 (CLs: 0.02, 0.19) fewer than nonpledgers, and 2.31\% (CLs: 0.08\%, 4.53\%) fewer pledgers reported having been paid for sex than nonpledgers.

Unmarried pledgers were less likely to report using birth control and condoms in the last year, and birth control at last sex, but did not differ in reporting condom use at last sex or in condom breakage (Table 2).

The pledgers and matched nonpledgers together are a highly religious group of adolescents and would be expected to be more sexually conservative. ${ }^{18-21}$ Pledgers and matched nonpledgers together reported substantially more conservative sexual behavior at wave 3 than the general population of adolescents - with fewer reporting premarital vaginal sex, oral and anal sex, birth control and condom use, and multiple sex partners and more reporting being married — but did not differ in 2 of the 3 STD tests: fewer had positive test results for Neisseria gonorrhoeae but did not differ in the proportion testing positive for Chlamydia trachomatis or Trichomonas vaginalis compared with the general adolescent population in Add Health wave 3 (data not shown). Among wave 2-matched nonpledgers, 8.7\% (CLs: 5.3\%, 12.1\%) reported a pledge at wave 3 . 


\section{DISCUSSION}

Pledgers were not less sexually active than matched nonpledgers despite prepledge similarities on 128 factors. Past findings that pledgers were less sexually active than the general population of nonpledgers may be attributable to regression models' failure to adjust for vast prepledge differences between the groups. Our refined sample (both pledgers and matched nonpledgers) is more religious and sexually conservative than the general population of adolescents and would be predicted to delay sex without virginity pledges. ${ }^{18-21}$

Despite having had similar birth control attitudes 1 year before pledging, virginity pledgers were substantially less likely than matched nonpledgers to protect themselves against STDs and pregnancy, consistent with earlier studies..$^{10,12}$

Virginity pledgers may be less likely to use condoms and contraception because many abstinence programs cause participants to develop negative attitudes about their effectiveness. 7,41

More than $90 \%$ of abstinence funding does not require that curricula be scientifically accurate, 6,9 and a 2004 review found incorrect information in 11 of 13 federally funded abstinence programs, primarily about birth control and condom effectiveness. ${ }^{42}$

Most virginity pledgers reported having had premarital vaginal and oral sex but did not seem to substitute oral and anal sex for vaginal sex, contrary to earlier studies. ${ }^{10}$ Virginity-pledge programs do not prepare pledgers to protect their health if they have sex, although most pledgers do have sex. Pledge programs have guidance for pledgers who initiate sex, such as the True Love Waits publication When True Love Doesn't Wait ${ }^{43}$ the recommendations of which include a medical examination and a second, mentored pledge.

Virginity pledgers have 0.1 fewer past-year sexual partners on average, but this modest difference is unlikely to affect STD risk, because pledgers do not differ in the average number of lifetime partners ( $\sim 3$ each) or age of sexual initiation (age 21$)$ or in empirical STD prevalence.

Few virginity pledgers continue to identify with their pledges 5 years after pledging, with $>80 \%$ claiming to have never pledged, consistent with an earlier finding that half of pledgers disaffiliated within 1 year. ${ }^{38}$ This high rate of disaffiliation may imply that nearly all virginity pledgers view pledges as nonbinding.

\section{Limitations}

Matching adjusts only for observed characteristics, but the finding of no difference is robust to matching adequacy. Even if unobserved differences remained after matching, the data could falsely indicate no difference between groups only if pledgers were less abstinent than nonpledgers. Differences between groups may be attributable to an unobserved characteristic, but large differences such as a 10 percentage-point difference in past-year condom use require finding unobserved characteristics with more effect than the 128 factors already matched on, which is unlikely. ${ }^{44}$

Outcome differences are biased toward showing a pledge effect, because the pledge is an intermediate variable to an unobserved treatment variable: abstinence education program participation, unmeasured in the Add Health survey. Approximately 5\% of the 32 outcomes compared may be statistically significant by chance because of multiple comparisons. These biases are unlikely to cause a full 10 percentage-point difference at all levels of condom use. 
Sexual behavior reports are likely biased toward showing a pledge effect because virginity pledgers may under-report se ${ }^{38}$; failure to observe a difference in sexual behavior reinforces the likelihood of no true difference.

Pledges were taken in 1996, but the prevalent pledge text and curriculum have not changed substantially since then, according to virginity pledge co-creator (Rev. James Hester, personal communication, September 20, 2007). Pledge programs differ in their educational programs, continued contact with pledgers, and possible effectiveness, but this study cannot differentiate among programs and computes an average difference over all programs.

Measurement is of self-reported virginity pledges, but within 1 year, half of the virginity pledgers denied having pledged. ${ }^{38}$ Adolescents who pledged and ended identification with the pledge before wave 2 were counted as nonpledgers, and $8.7 \%$ of wave 2 nonpledgers reported a pledge at wave 3 ; these bias results to show no pledge effect.

Adolescents were $\geq 15$ years of age at wave 1 because of unavailability of sex and contraceptive attitude data for younger adolescents. Younger virginity pledgers may be more likely to delay sex over a period of 1 year, as a previous study found, ${ }^{12}$ but as was true for older adolescents, part of the delay is likely attributable to pledgers' prepledge attitudes, not the pledge.

Premarital sex, condom, and birth control use cannot be detected for married respondents and were not imputed. Anal and oral sex prevalence come from respondents' descriptions of each of their past relationships and, thus, are likely to be underestimates: $75 \%$ of respondents reported having had vaginal sex, but only $63.8 \%$ of respondents reported vaginal sex in describing past relationships.

This article maximizes internal validity, with sacrifice to external: the restricted subsample is not nationally representative.

\section{Policy Implications}

The results suggest that the virginity pledge does not change sexual behavior. One cannot make causal inferences given the pledge's voluntary nature, but if the pledge decreased sexual activity, we would expect to observe a difference between virginity pledgers and comparable nonpledgers; indeed, this estimate is biased in favor of showing a pledge effect.

Given this evidence that pledgers are less likely than comparable nonpledgers to use condoms and birth control, and previous evidence that AOSE programs do not affect sexual behavior,

7,8 federal AOSE funds should be shifted to evidence-based sex education programs that teach birth control and have been demonstrated to delay sexual initiation ${ }^{3,4}$ and increase safer sex practices. ${ }^{1,3-5}$

Virginity pledges are not a marker for less sexual activity and should not be used as a measure of abstinence sex education program effectiveness.

\section{CONCLUSIONS}

Adolescents who take virginity pledges are not less sexually active than closely matched adolescents who do not take pledges, but they are less likely to use birth control and condoms. Clinicians should provide birth control information to all adolescents, especially AOSE participants. 


\section{Acknowledgments}

This work was supported by the Milton Fund of Harvard Medical School (Michael Ganz, principal investigator), the Harvard Graduate School of Arts and Sciences, the Harvard PhD Program in Health Policy, the Department of Society, Human Development, and Health at the Harvard School of Public Health, and the Institute for Health Research and Policy at the University of Illinois at Chicago.

I am grateful for the guidance of my dissertation committee: Joanne Cox, Don Rubin, Kimberly Thompson, and Alan Zaslavsky. I thank the following individuals for helpful discussions: Bob Blum, Barbara Devaney, Michael Ganz, Mark Goldstein, Jim Greiner, David Hemenway, Jim Hester, Charles Horn, Olivia Lau, Rebekah Maggor, Richard Ross, Joe Schafer, Kathy Swartz, Chris Trenholm, Chris Winship, Laurie Zabin, and anonymous reviewers.

\section{APPENDIX}

Tables 3 through 5 show factors considered as potential predictors of taking a virginity pledge, categorized according to their origin. Potential predictors of taking a virginity pledge were derived from the past virginity-pledge literature and the National Institute of Mental Health integrated model for health behavior. Potential predictors are listed under model components as an aid to the reader, although many other categorizations are possible. Covariates were added separately to the logistic regression model in a "flat" manner, so their categorization did not influence the logistic regression model for predicting probability of pledging. All variables were included in the propensity score model separately, rather than in index format. Variables were combined into indices so that they are continuous for use in the nearest-neighbor matching. All binary variables were defined as 1 if endorsed and 0 otherwise.

Table 6 shows the logistic regression model results predicting taking a wave 2 virginity pledge from wave 1 characteristics. The logistic regression model was determined from stepwise logistic regression in Stata by using the factors listed in Tables 3 through 5.

Tables 7 through 10 show the means before and after matching for each of the variables listed in Tables 3 through 5. These tables were extracted into Table 1.

\section{Variable Selection}

The following details how variables were selected by using the past pledge literature ${ }^{11-14}$ and the National Institute of Mental Health integrated health behavior model. ${ }^{33}$

The past pledge literature was used for identifying variables associated with pledging. I attempted to use all available variables in every article that examined predictors of pledging and all significant variables.

\section{Variable Coding and Missing Data}

All items were coded for endorsement or nonendorsement; skipping a question counted as nonendorsement. Peabody vocabulary scores and parent-reported household incomes were median-imputed, and an indicator for missingness was created. Height and weight were imputed by using regression on age, gender, interaction, and each other and median-imputed for the remaining cases. Median imputation artificially decreases SE and may cause a nonsignificant factor to be included in the matching model, but that does not compromise match quality. Sex and birth control outcomes for respondents who never had sex were coded as missing. The number of lifetime and past-year sex partners was truncated at the 90th percentile for each gender: females at 8 lifetime and 2 past-year partners and males at 10 and 3 , respectively. Past-year and lifetime partners and age of first sex at wave 3 were each skipped by $<1 \%$ of respondents; number of times the respondent had sex in the past year was skipped by $7 \%$ of respondents. These continuous outcomes were regression-imputed by using wave 1 
age, gender, race/ethnicity, church attendance, and parent education and income as predictors. Because pregnancy and STD prevention are generally unimportant for married respondents, these questions were coded as missing for respondents unmarried at wave 3.

\section{Abbreviations}

STD, sexually transmitted disease; AOSE, abstinence-only sex education; CL, confidence limit.

\section{REFERENCES}

1. Kirby, D. Emerging Answers 2007: Research Findings on Programs to Reduce Teen Pregnancy and Sexually Transmitted Diseases. National Campaign to Prevent Teen Pregnancy; Washington, DC: 2007.

2. Sandfort TG, Orr M, Hirsch JS, Santelli J. Long-term health correlates of timing of sexual debut: results from a national US study. Am J Public Health 2008;98(1):155-161. [PubMed: 18048793]

3. Santelli J, Ott MA, Lyon M, Rogers J, Summers D, Schleifer R. Abstinence and abstinence-only education: a review of US policies and programs. J Adolesc Health 2006;38(1):72-81. [PubMed: 16387256]

4. Kirby DB, Laris BA, Rolleri LA. Sex and HIV education programs: their impact on sexual behaviors of young people throughout the world. J Adolesc Health 2007;40(3):206-217. [PubMed: 17321420]

5. Underhill K, Operario D, Montgomery P. Systematic review of abstinence-plus HIV prevention programs in high-income countries. PLoS Med 2007;4(9):e275. [PubMed: 17880259]Available at: http://medicine.plosjournals.org/perlserv/?request=get-document\&doi=10.1371/journal.pmed. $0040275 \& c t=1$. Accessed January 14, 2008

6. Government Accountability Office. Abstinence Education: Efforts to Assess the Accuracy and Effectiveness of Federally-Funded Programs, October 2006. GAO-07-87. Available at: www.gao.gov/cgibin/getrpt?GAO-07-87. Accessed October 15, 2007

7. Trenholm, C.; Devaney, B.; Forston, K.; Quay, L.; Wheeler, J.; Clark, M. Impacts of four Title V, Section 510 abstinence education programs. Mathematica Policy Res. Apr. 2007 Available at: www.mathematica-mpr.com/publications/PDFs/impactabstinence.pdf. Accessed January 14, 2008

8. Underhill K, Operario D, Montgomery P. Sexual abstinence only programmes to prevent HIV infection in high income countries: systematic review. BMJ 2007;335(7613):248. [PubMed: 17656503]

9. Department of Health and Human Services. HHS Budget in Brief 2008. Available at: www.hhs.gov/budget/08budget/2008BudgetInBrief.pdf. Accessed June 23, 2008

10. Bearman PS, Brückner H. After the promise: the STD consequences of adolescent virginity pledges. J Adolesc Health 2005;36(4):271-278. [PubMed: 15780782]

11. Constantine, NA.; Braverman, MT. Appraising evidence on program effectiveness. In: Braverman, MT.; Constantine, NA.; Slater, JK., editors. Foundations and Evaluation: Contexts and Practices for Effective Philanthropy. Jossey-Bass; San Francisco, CA: 2004. p. 236-258.

12. Bearman PS, Brückner H. Promising the future: virginity pledges and first intercourse. Am J Sociol 2001;106(4):859-912.

13. Ford CA, Pence BW, Miller WC, et al. Predicting adolescents' longitudinal risk for sexually transmitted infection: results from the National Longitudinal Study of Adolescent Health. Arch Pediatr Adolesc Med 2005;159(7):657-664. [PubMed: 15997000]

14. Bersamin MM, Walker S, Waiters ED, Fisher DA, Grube JW. Promising to wait: virginity pledge and adolescent sexual behavior. J Adolesc Health 2005;36(5):428-436. [PubMed: 15837347]

15. Lalonde R. Evaluating the econometric evaluations of training programs. Am Econ Rev 1986;76(4): 605-620.

16. Dehejia HR, Wahba S. Causal effects in nonexperimental studies: reevaluating the evaluation of training programs. J Am Stat Assoc 1999;94(448):1053-1062.

17. Rosenbaum, PR. Matching in observational studies. In: Gelman, A.; Meng, XL., editors. Applied Bayesian Modeling and Causal Inference From Incomplete-Data Perspectives. John Wiley and Sons; Chicester West Sussex, England: 2004. p. 5-24. 
18. Miller L, Gur M. Religiousness and sexual responsibility in adolescent girls. J Adolesc Health 2002;31 (5):401-406. [PubMed: 12401426]

19. Nonnemaker JM, McNeely CA, Blum RW. Public and private domains of religiosity and adolescent health risk behaviors: evidence from the National Longitudinal Study of Adolescent Health. Soc Sci Med 2003;57(11):2049-2054. [PubMed: 14512236]

20. Jones RK, Darroch JE, Singh S. Religious differentials in the sexual and reproductive behaviors of young women in the United States. J Adolesc Health 2005;36(4):279-288. [PubMed: 15780783]

21. Lain MT, Wang J, Barry M. A longitudinal study of adolescent transition from virgin to nonvirgin status. J Adolesc Health 2008;42(3):228-236. [PubMed: 18295130]

22. Rubin, DB. Matched Sampling for Causal Effects. Cambridge University Press; New York, NY: 2006.

23. Morgan, SL.; Winship, C. Counterfactuals and Causal Inference: Methods and Principles for Social Research. Cambridge University Press; New York, NY: 2007.

24. Gelman, A.; Hill, J. Data Analysis Using Regression and Multilevel/Hierarchical Models. Cambridge University Press; New York, NY: 2007.

25. Ho D, Imai K, King G, Stuart E. Matching as nonparametric preprocessing for reducing model dependence in parametric causal inference. Polit Anal 2007;15(3):199-126.Available at: http://gking.harvard.edu/utiles/abs/maTchp-abs.shtml. Accessed May 4, 2008

26. Imai K, King G, Stuart EA. Misunderstandings among experimentalists and observationalists about causal inference. J R Stat Soc Ser A Stat Soc 2008;171(2):481-502.Available at: http://imai.princeton.edu/research/balance.html. Accessed May 7, 2008

27. Rubin DB. Estimating causal effects from large data sets using propensity scores. Ann Intern Med 1997;127(8 pt 2):757-763. [PubMed: 9382394]

28. Little RJ, Rubin DB. Causal effects in clinical and epidemiological studies via potential outcomes: concepts and analytical approaches. Annu Rev Public Health 2000;21:121-145. [PubMed: 10884949]

29. Rubin DB. The design versus the analysis of observational studies for causal effects: parallels with the design of randomized trials. Stat Med 2007;26(1):20-36. [PubMed: 17072897]

30. Austin PC. A critical appraisal of propensity-score matching in the medical literature between 1996 and 2003. Stat Med 2008;27(12):2037-2049. [PubMed: 18038446]

31. Stuart EA. Developing practical recommendations for the use of propensity scores: discussion of a critical appraisal of propensity-score matching in the medical literature between 1996 and 2003. Stat Med 2008;27(12):2062-2065. [PubMed: 18286673]

32. Hansen BB. The essential role of balance tests in propensity-matched observational studies: comments on a critical appraisal of propensity-score matching in the medical literature between 1996 and 2003. Stat Med 2008;27(12):2050-2054. [PubMed: 18407561]

33. Hill J. Discussion of research using propensity score matching: comments on a critical appraisal of propensity-score matching in the medical literature between 1996 and 2003. Stat Med 2008;27(12): 2055-2061. [PubMed: 18446836]

34. Austin PC, Grootendorst P, Anderson GM. A comparison of the ability of different propensity score models to balance measured variables between treated and untreated subjects: a Monte Carlo study. Stat Med 2007;26(4):734-753. [PubMed: 16708349]

35. Udry, JR. The National Longitudinal Study of Adolescent Health (Add Health), Waves I \& II, 19941996; Wave III, 2001-2002 [machine-readable data file and documentation]. Carolina Population Center, University of North Carolina; Chapel Hill, NC: 2003.

36. Tourangeau, R.; Shin, HC. National Longitudinal Study of Adolescent Health: Grand Sample Weight. Carolina Population Center, University of North Carolina; Chapel Hill, NC: 1999.

37. Jaccard J, Dodge T, Dittus P. Parent-adolescent communication about sex and birth control: a conceptual framework. New Dir Child Adolesc Dev 2002;97(97):9-41. [PubMed: 14964942]

38. Rosenbaum JE. Reborn a virgin: adolescents' retracting of virginity pledges and sexual histories. Am J Public Health 2006;96(6):1098-1103. [PubMed: 16670225]

39. Ho, D.; Imai, K.; King, G.; Stuart, E. MatchIt: Nonparametric Preprocessing for Parametric Causal Inference. Version 2.3-1. Available at: http://gking.harvard.edu/matchit. Accessed May 13, 2008 
40. Cohen, J. Statistical Power Analysis for the Behavioral Sciences. Vol. 2nd ed.. Lawrence Erlbaum Associates; Hillsdale, NJ: 1988.

41. Borawski, EA.; Colabianchi, N.; Levers-Landis, CE., et al. First year outcomes of Healthy Teens Building Healthy Schools: an abstinence-until-marriage vs comprehensive sex education intervention study [abstract]; Presented at: the American Public Health Association 133rd annual meeting; Philadelphia, PA. December 10-14, 2005; Abstract 108124

42. United States House of Representatives Committee on government reform, minority staff special investigations division. The Content of Federally-Funded Abstinence-Only Education Programs. Prepared for Rep. Henry A. Waxman, December 2004

43. Rankin, DT. When True Love Does'nt Wait. LifeWay Christian Resources; Nashville, TN: 1998.

44. Rosenbaum, PR. Observational Studies. Vol. 2nd ed.. Springer; New York, NY: 2002. 


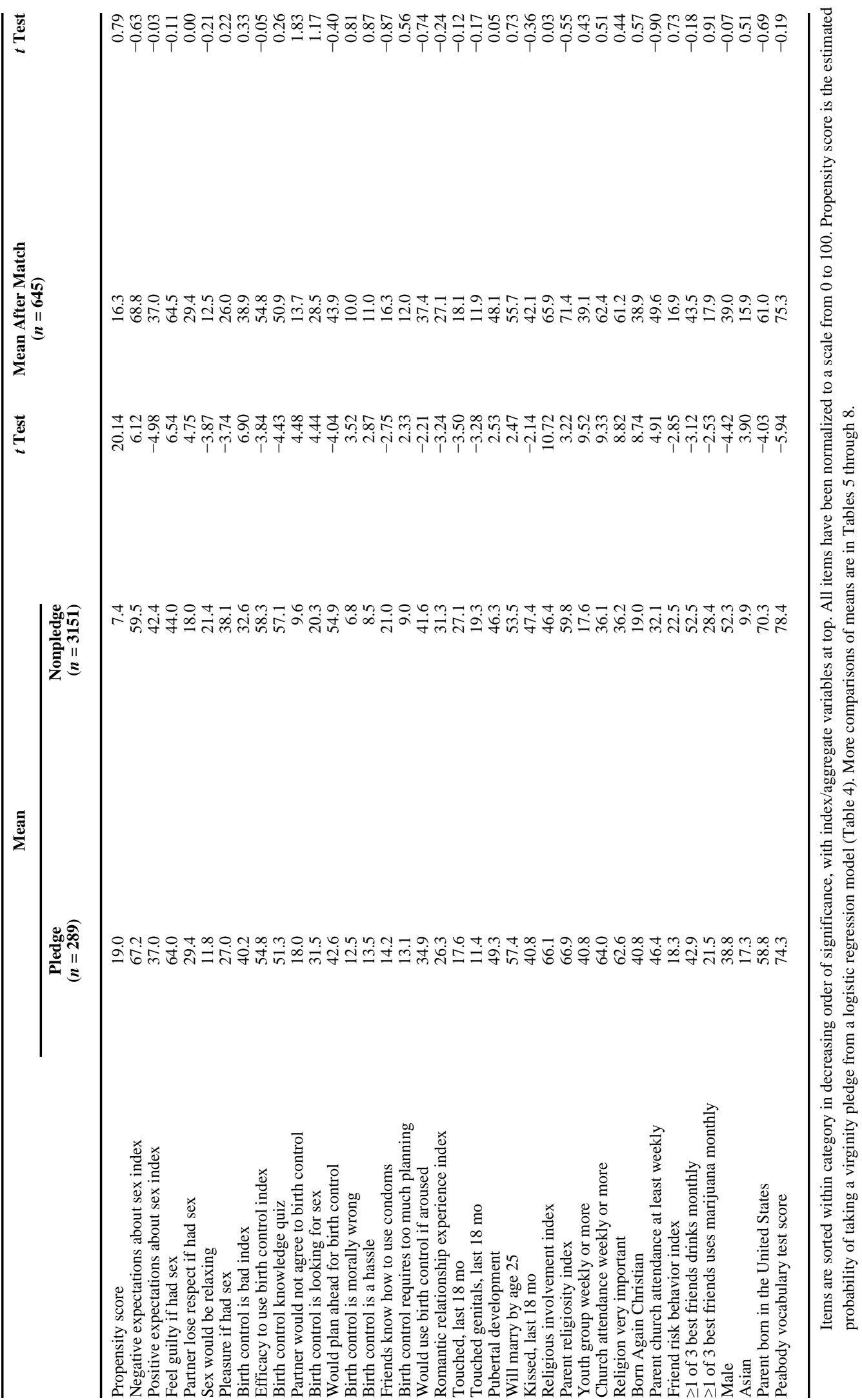

Pediatrics. Author manuscript; available in PMC 2009 October 27. 
TABLE 2

Sexual Behavior and Birth Control Use for Pledgers and Matched Nonpledgers, Wave 3

\begin{tabular}{|c|c|c|c|}
\hline & \multicolumn{2}{|r|}{$\Delta(95 \%$ CLs $)$} & \multirow[t]{2}{*}{$t$ Test $($ Effect Size $d)$} \\
\hline & Pledge $(n=289)$ & Nonpledge $(n=645)$ & \\
\hline Sexual intercourse & $72.66(2.63)$ & $76.24(1.69)-3.58(-9.58,2.43)$ & -1.21 \\
\hline Premarital sex and unmarried & $53.29(2.94)$ & $57.09(1.96)-3.81(-10.70,3.09)$ & -1.08 \\
\hline $\begin{array}{l}\text { Number times had sex in past } \\
\text { year }\end{array}$ & $22.83(0.80)$ & $23.68(0.55)-0.84(-2.76,1.07)$ & -0.86 \\
\hline Age first sex, y & $21.23(0.33)$ & $20.73(0.22) 0.49(-0.28,1.26)$ & 1.25 \\
\hline Lifetime partners & $3.22(0.14)$ & $3.52(0.09)-0.31(-0.63,0.02)$ & -1.86 \\
\hline Past year partners & $1.09(0.03)$ & $1.20(0.02)-0.11(-0.19,-0.02)$ & $-2.45(0.28)$ \\
\hline $\begin{array}{l}\text { Sexual intercourse, in } \\
\text { relationship }\end{array}$ & $64.36(2.82)$ & $63.55(1.90) 0.81(-5.87,7.48)$ & 0.24 \\
\hline Receive anal sex, in relationship & $9.00(1.69)$ & $10.27(1.20)-1.27(-5.41,2.87)$ & -0.60 \\
\hline Give anal sex, in relationship & $6.23(1.42)$ & $4.50(0.82) 1.73(-1.31,4.77)$ & 1.12 \\
\hline Receive oral sex, in relationship & $59.17(2.90)$ & $57.09(1.96) 2.08(-4.78,8.94)$ & 0.59 \\
\hline Give oral sex, in relationship & $50.87(2.95)$ & $51.33(1.97)-0.46(-7.40,6.48)$ & -0.13 \\
\hline Ever have partner with STD & $3.46(1.08)$ & $5.42(0.90)-1.96(-4.93,1.01)$ & -1.29 \\
\hline Ever paid someone for sex & $1.73(0.77)$ & $2.77(0.65)-1.04(-3.18,1.11)$ & -0.95 \\
\hline Ever been paid for sex & $1.04(0.60)$ & $3.34(0.71)-2.31(-4.53,-0.08)$ & $-2.03(0.21)$ \\
\hline Chlamydia test & $2.42(0.84)$ & $4.25(0.74)-1.83(-4.26,0.61)$ & -1.47 \\
\hline Trichomoniasis test & $2.04(0.77)$ & $2.13(0.53)-0.09(-1.94,1.76)$ & -0.10 \\
\hline Gonorrhea test & 0.00 & 0.000 .00 & \\
\hline Ever marry & $20.42(2.38)$ & $20.42(1.59) 0.00(-5.60,5.60)$ & 0.00 \\
\hline Ever divorce & $2.08(0.84)$ & $1.50(0.48) 0.58(-1.21,2.36)$ & 0.63 \\
\hline Ever attracted to same sex & $8.30(1.63)$ & $9.69(1.17)-1.38(-5.41,2.64)$ & -0.67 \\
\hline Identify as gay or bisexual & $3.81(1.13)$ & $3.69(0.74) 0.12(-2.52,2.75)$ & 0.09 \\
\hline Always use condom past year & $23.91(2.13)$ & $34.49(1.66)-10.58(-16.11,-5.05)$ & $-3.75(0.35)$ \\
\hline$\geq$ Most of the time use condom & $42.03(2.46)$ & $53.70(1.75)-11.67(-17.64,-5.71)$ & $-3.84(0.35)$ \\
\hline$\geq$ Half the time use condom & $50.72(2.49)$ & $61.81(1.70)-11.08(-16.96,-5.20)$ & $-3.70(0.33)$ \\
\hline Never use condom, past year & $28.26(2.25)$ & $19.68(1.39) 8.58(3.62,13.55)$ & $3.39(0.30)$ \\
\hline Always use birth control past year & $45.65(2.48)$ & $51.62(1.72)-5.97(-11.93,-0.01)$ & $-1.96(0.18)$ \\
\hline $\begin{array}{l}\geq \text { Most of the time use birth } \\
\text { control }\end{array}$ & $63.77(2.40)$ & $70.14(1.58)-6.37(-11.92,-0.82)$ & $-2.25(0.20)$ \\
\hline$\geq$ Half the time use birth control & $69.57(2.30)$ & $75.93(1.47)-6.36(-11.59,-1.13)$ & $-2.38(0.21)$ \\
\hline Never use birth control, past year & $15.22(1.79)$ & $14.12(1.19) 1.10(-3.10,5.29)$ & 0.51 \\
\hline Last sex use condom & $52.17(2.49)$ & $54.86(1.70)-2.69(-8.63,3.26)$ & -0.89 \\
\hline Last sex use birth control & $66.67(2.35)$ & $72.22(1.54)-5.56(-10.99,-0.12)$ & $-2.00(0.33)$ \\
\hline Past year had condom break & $26.85(1.96)$ & $25.71(1.34) 1.14(-3.55,5.82)$ & 0.48 \\
\hline
\end{tabular}

All quantities are percentage endorsing, except number of sexual partners and age at first sex. Means and SE are weighted according to frequency. $\Delta$ is the difference in means of pledgers and nonpledgers. Comparison of birth control is restricted to singles who have had sex $(n=154$ pledgers, 393 nonpledgers). Cohen's effect size $d$ is computed for significant differences. 
TABLE 3

Factors From the Literature Considered As Potential Predictors of Virginity Pledge

\begin{tabular}{|c|c|}
\hline Factor & Variables \\
\hline Demographics & $\begin{array}{l}\text { Gender } \\
\text { Age } \\
\text { Region } \\
\text { Born in United States } \\
\text { Black, Asian, Latino } \\
\text { BMI } \\
\text { Height } \\
\text { Height } z \text { score for age }\end{array}$ \\
\hline $\begin{array}{l}\text { Parent-reported (child proxy, } \\
\text { if missing) }\end{array}$ & $\begin{array}{l}\text { Parent education } \\
\text { Public assistance } \\
\text { Household income, income missing } \\
\text { Enough money to pay bills } \\
\text { Parent born in United States }\end{array}$ \\
\hline Family & $\begin{array}{l}\text { Live with biological mother, father, both } \\
\text { Close to mother/father } \\
\text { Mother/father warm and loving } \\
\text { Satisfied with communication with mother/ } \\
\text { father } \\
\text { Satisfied with relationship with mother/ } \\
\text { father } \\
\text { Mother encourages independence } \\
\text { Mother explains if do something wrong }\end{array}$ \\
\hline School attachment & $\begin{array}{l}\text { Close to others at school } \\
\text { Belong to school community } \\
\text { Get along with other students, teachers } \\
\text { Number of school sports participate in }\end{array}$ \\
\hline
\end{tabular}

Parent-reported income was not significant in any model and was missing for many respondents. Thus, stepwise regressions were all repeated with it omitted and results did not differ, so household income was not used in the final model. Family variables are defined as 0 for respondents without the specified parent. 
TABLE 4

Factors From the National Institute of Mental Health Integrated Health Behavior Model: Intention to Abstain

\begin{tabular}{|c|c|c|}
\hline Model Component & Factor & Variables \\
\hline Attitude & Attitude toward birth control & $\begin{array}{l}\text { Partner would not use } \\
\text { Friends see birth control as "looking for sex" } \\
\text { Birth control morally wrong, difficult to use } \\
\text { Birth control expensive, requires planning, interferes } \\
\text { Mother would disapprove }\end{array}$ \\
\hline \multirow[t]{3}{*}{ Sexual expectations } & Positive psychosocial & $\begin{array}{l}\text { If had sex, would have pleasure } \\
\text { Gain respect, be more attractive } \\
\text { Feel less lonely, feel relaxing }\end{array}$ \\
\hline & Negative psychosocial & $\begin{array}{l}\text { Would lose partner's respect } \\
\text { Feel guilty, upset mother }\end{array}$ \\
\hline & Risks & $\begin{array}{l}\text { Probability pregnancy, } 1 \text { act unprotected sex } \\
\text { Probability HIV, } 1 \text { mo unprotected sex } \\
\text { Chances of HIV, STD }\end{array}$ \\
\hline Emotions about sex & & Expectations of pleasure, lonely, relaxing, guilty \\
\hline \multirow[t]{2}{*}{ Self-image } & Personal religiosity & $\begin{array}{l}\text { Prayer frequency, religion important } \\
\text { Bible literally true, Born Again Christian }\end{array}$ \\
\hline & Life expectations & $\begin{array}{l}\text { Want to attend college } \\
\text { Will attend college, marry by age } 25 \\
\text { Live to age } 35 \text {, killed by age } 21 \text {, get HIV }\end{array}$ \\
\hline \multirow[t]{2}{*}{ Self-efficacy } & Birth control efficacy & $\begin{array}{l}\text { Would use birth control; would plan ahead to use, resist sex } \\
\text { without birth control }\end{array}$ \\
\hline & General efficacy & $\begin{array}{l}\text { Lots of energy, seldom sick, recover quickly, well- } \\
\text { coordinated, lots of good qualities, } \\
\text { physically fit, lots to be proud of like self as are, doing } \\
\text { everything just about right } \\
\text { Socially accepted, loved, and wanted }\end{array}$ \\
\hline \multirow[t]{3}{*}{ Social norms } & $\begin{array}{l}\text { Religious behavior } \\
\text { Parent religiosity }\end{array}$ & $\begin{array}{l}\text { Youth group, religious service attendance } \\
\text { Church attendance, religion important } \\
\text { Prayer frequency, Bible divine }\end{array}$ \\
\hline & Delinquency & Drinking, trouble with school peers and teachers \\
\hline & Friend risks & $\begin{array}{l}\text { Number of friends who smoke daily, use marijuana and } \\
\text { alcohol monthly, attempt suicide }\end{array}$ \\
\hline
\end{tabular}


TABLE 5

Factors From the National Institute of Mental Health Integrated Health Behavior Model: Knowledge/Skills, Absence Environmental Constraints, Salience, Habit

\begin{tabular}{|c|c|c|}
\hline Model Component & Factor & Variables \\
\hline \multirow[t]{3}{*}{ Knowledge/skills } & General knowledge & $\begin{array}{l}\text { Peabody vocabulary test score (median-imputed) } \\
\text { Grade-point average (nonmissing grades) }\end{array}$ \\
\hline & Birth control knowledge & 10 -item quiz on condom use and pregnancy risk \\
\hline & Health education & $\begin{array}{l}\text { Learned in school about HIV, STDs, pregnancy, drug abuse, } \\
\text { drinking, suicide }\end{array}$ \\
\hline Absence constraints & Romantic history & $\begin{array}{l}\text { Relationship past } 18 \text { mo } \\
\text { Tell someone like/love, hold hands, kiss, consider self part } \\
\text { of couple, touch on or } \\
\text { under clothing, touch genitals }\end{array}$ \\
\hline Salience & Pubertal development & $\begin{array}{l}\text { Female: breast, body development; menarche } \\
\text { Male: facial, body hair; voice change } \\
\text { Both: appearance relative to same-age peers } \\
\text { Items averaged and scaled } 0 \text { to } 1 \text {, not analyzed separately }\end{array}$ \\
\hline Habit & $\begin{array}{l}\text { Religious involvement } \\
\text { Abstinence }\end{array}$ & $\begin{array}{l}\text { Attendance youth group, religious services } \\
\text { All subjects have never had intercourse, so are abstaining } \\
\text { from sexual intercourse }\end{array}$ \\
\hline
\end{tabular}

The 3 sex-specific components of the puberty index are asked in an absolute way, but in a linear regression pubertal development is associated with gender, but not age, and only marginally associated with an interaction between age and gender. Respondents may answer these questions with reference to other people their age regardless of the absolute wording of the question. 
TABLE 6

Logistic Regression Results: Prepledge Characteristics (Wave 1) Associated With Taking a Virginity Pledge (Wave 2)

Odds Ratio (95\% CLs)

Live with both biological parents

$0.55(0.42,0.73)$

Parents born in United States ${ }^{a}$

$0.67(0.47,0.95)$

Male $^{a}$

Age, $\mathrm{y}^{a}$

Born in United States

White

Asian

West region

Puberty score

Vocabulary test score (maximum: 100) ${ }^{a}$

Lots of good qualities ${ }^{a}$

Teachers fair

Socially accepted

Feel loved

Born Again Christian ${ }^{a}$

Weekly youth group attendance ${ }^{a}$

Weekly church attendance ${ }^{a}$

Religion is very important ${ }^{a}$

Parent attends church at least monthly

Sex would make feel guilty ${ }^{a}$

If I used birth control people would think

I had been looking for sex ${ }^{a}$

$0.68(0.51,0.92)$

$0.85(0.74,0.97)$

$0.75(0.49,1.14)$

$1.27(0.92,1.76)$

$1.43(0.90,2.26)$

$1.33(0.97,1.81)$

$2.06(0.99,4.26)$

$0.99(0.97,1.00)$

$0.39(0.15,1.00)$

$1.77(1.02,3.07)$

$2.32(0.97,5.54)$

$1.78(0.70,4.48)$

$1.93(1.43,2.60)$

$1.65(1.21,2.24)$

$1.57(1.13,2.17)$

$1.41(1.05,1.91)$

$1.27(0.94,1.71)$

$1.49(1.12,1.97)$

Would plan ahead for birth control ${ }^{a}$

Friends know how to use condoms $a$

$1.49(1.11,1.99)$

$0.68(0.50,0.90)$

$0.62(0.43,0.90)$

$0.66(0.44,0.99)$

Sex would be relaxing

Birth control knowledge quiz score ${ }^{a}$

Would not have sex without birth control

$0.53(0.29,0.98)$

$1.33(0.98,1.79)$

Will marry by age

$251.40(0.85,2.33)$

Data are from respondents who at wave 1 had not taken a virginity pledge, never had sex, and were at least 15 years of age $(n=3440)$. Factors shown are from logistic regression with $P<.2$. All variables except age and vocabulary test score are on a scale of 0 to 1 . Variables are grouped by theme and sorted according to significance.

${ }^{a}$ Factors significant at $P<.05$ 


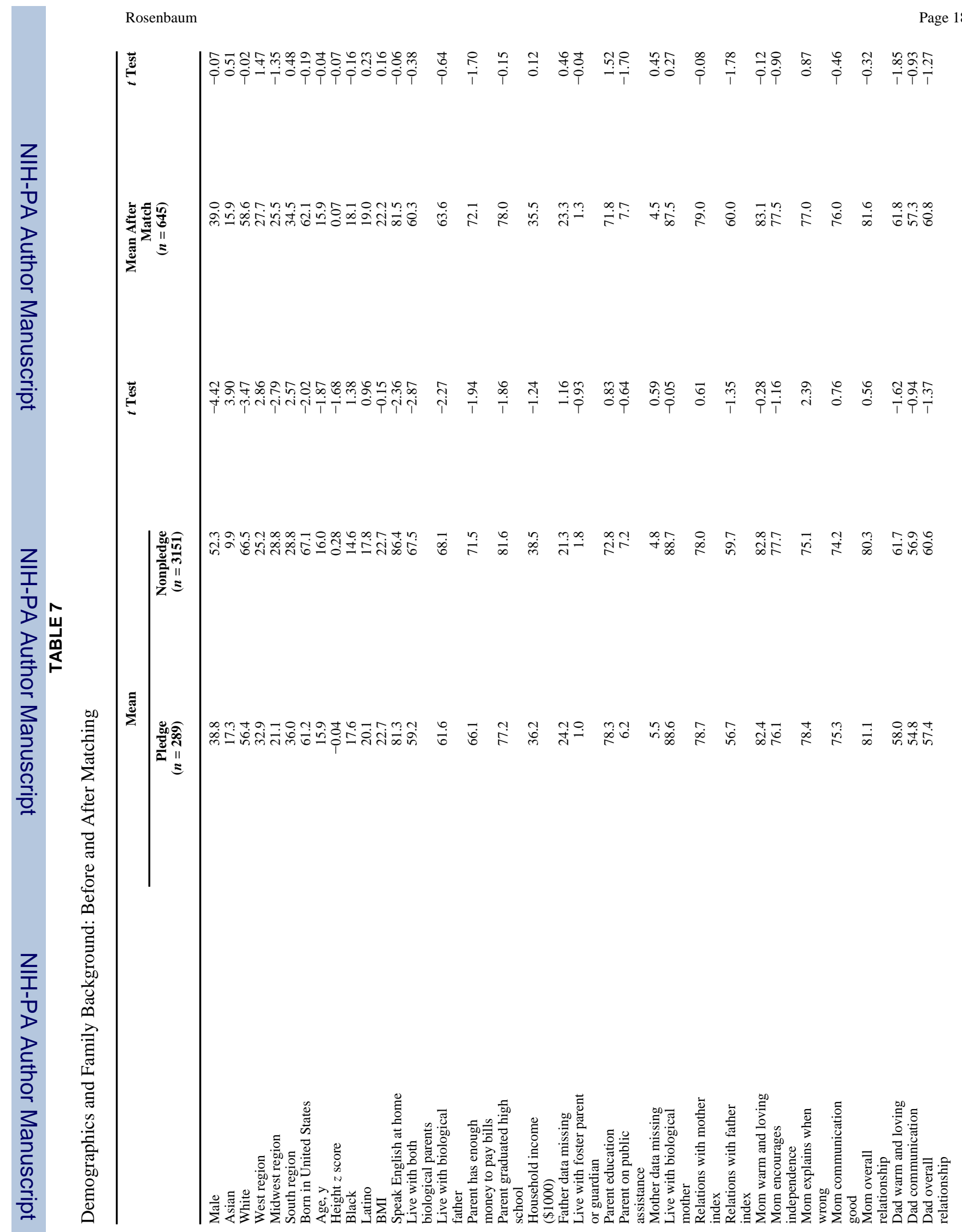

Pediatrics. Author manuscript; available in PMC 2009 October 27. 


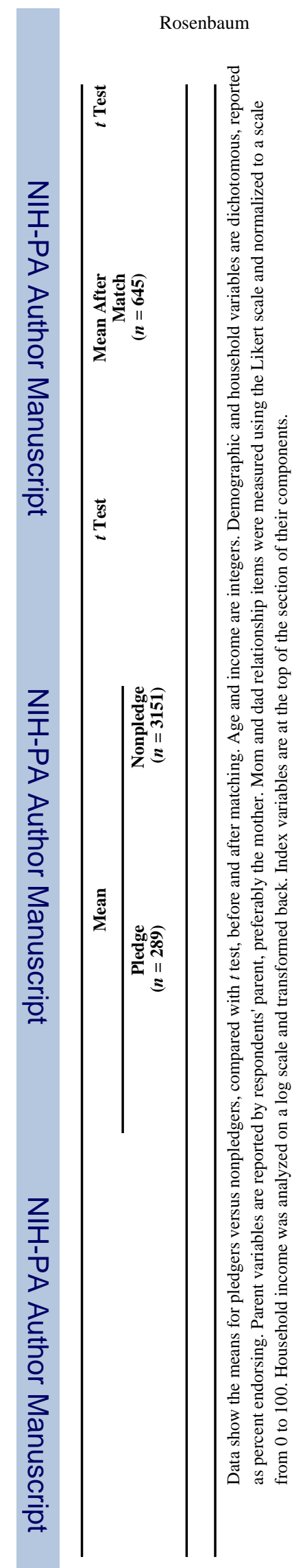

Page 19 


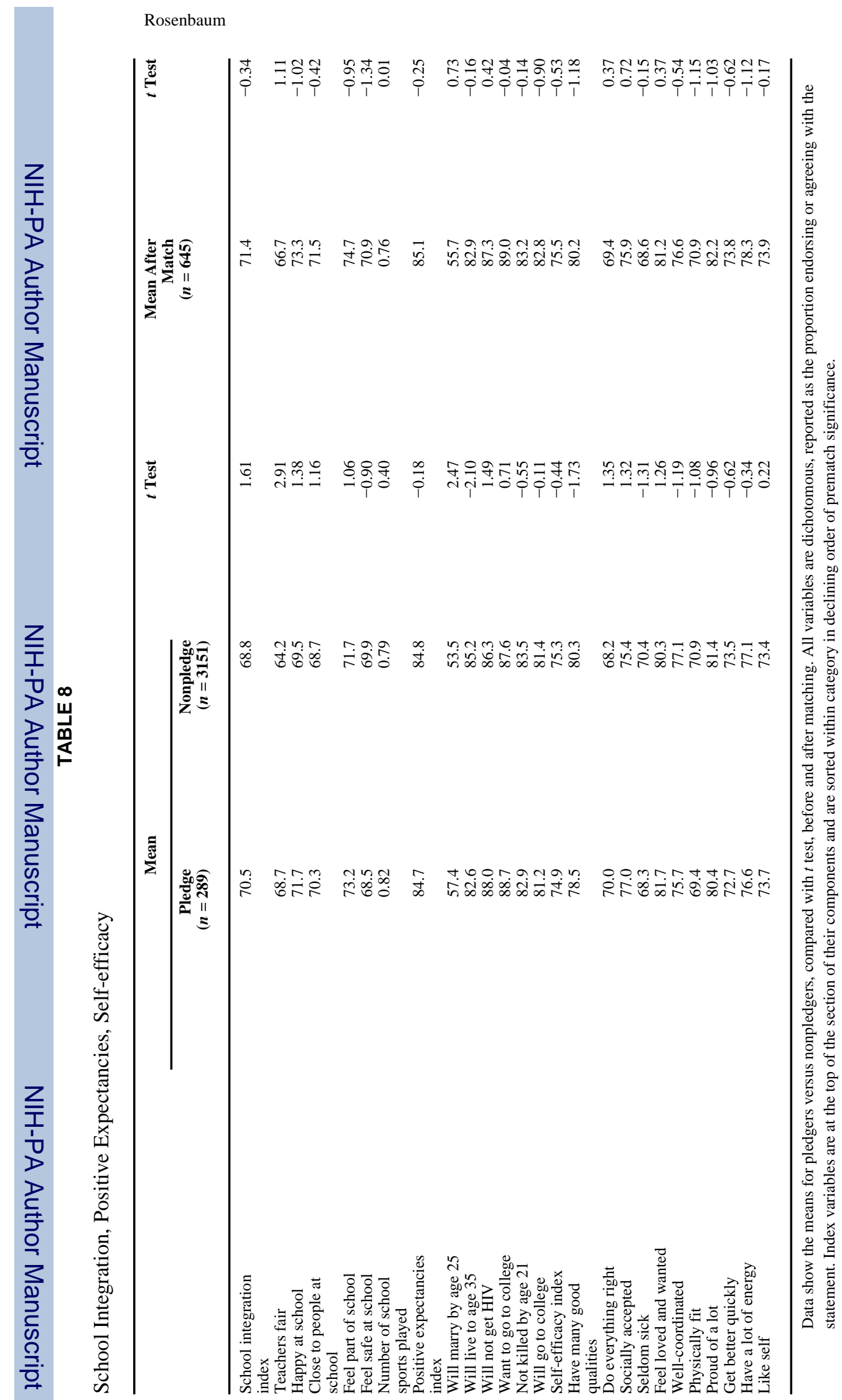

Page 20 


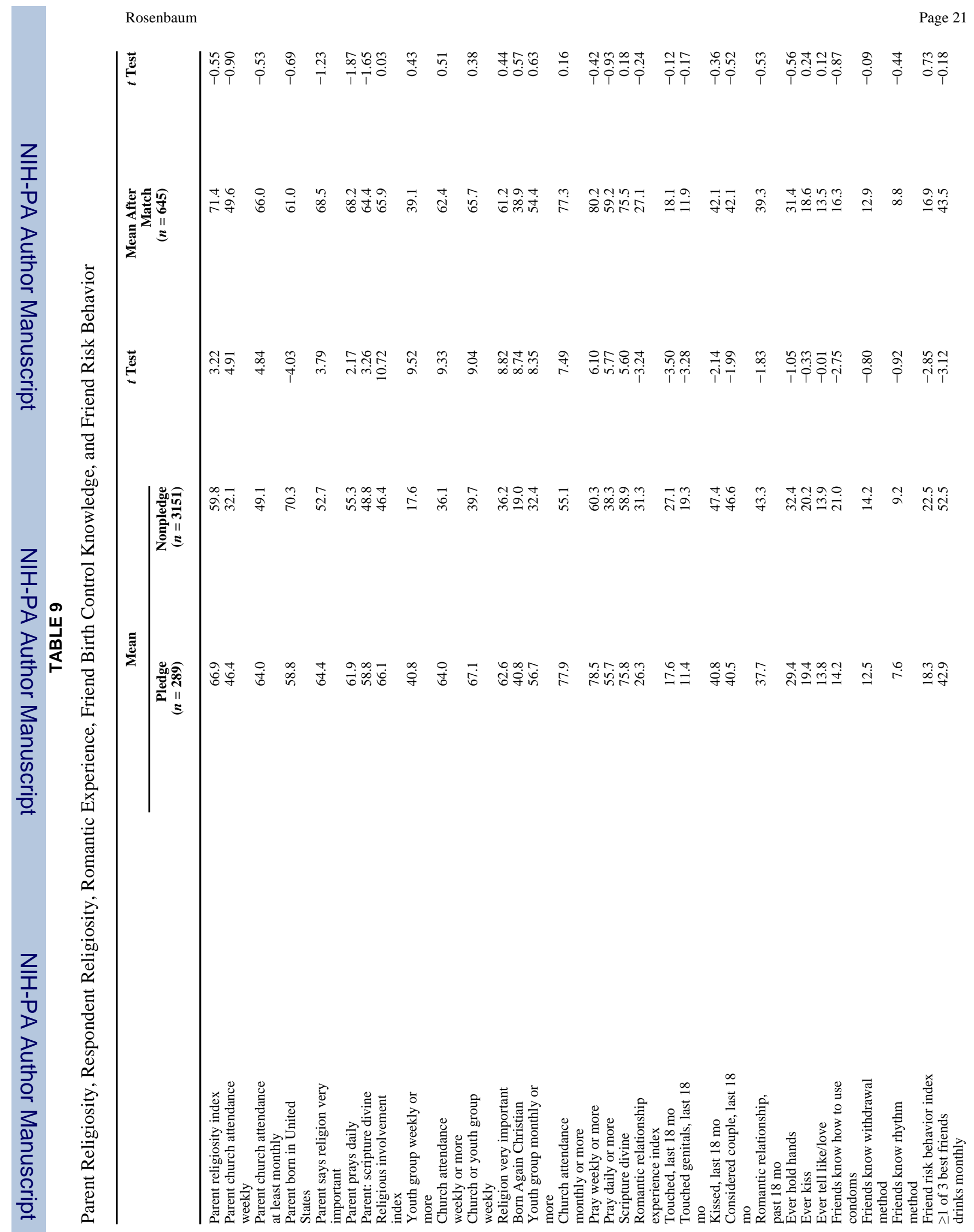

Pediatrics. Author manuscript; available in PMC 2009 October 27. 


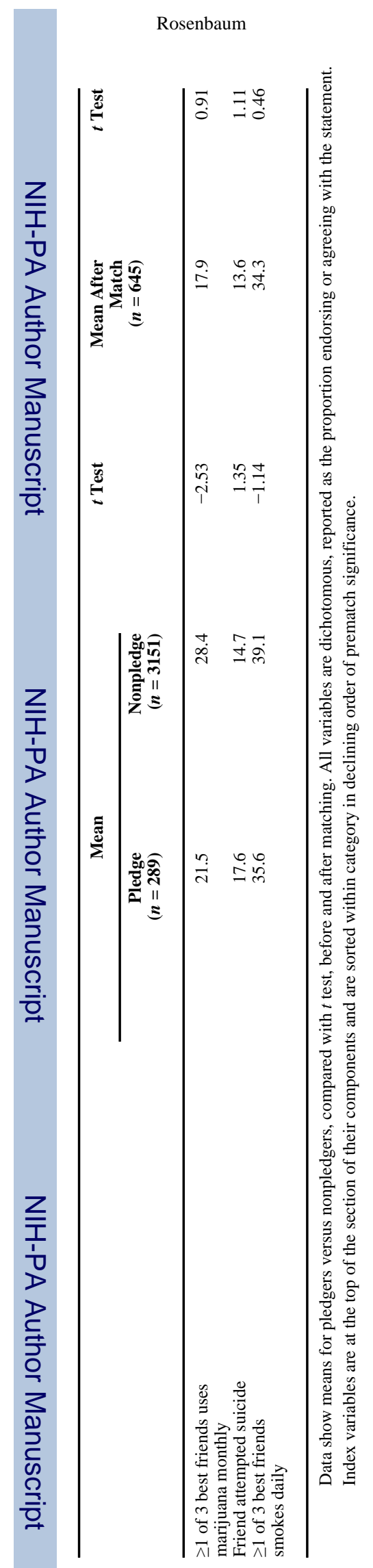

Page 22 


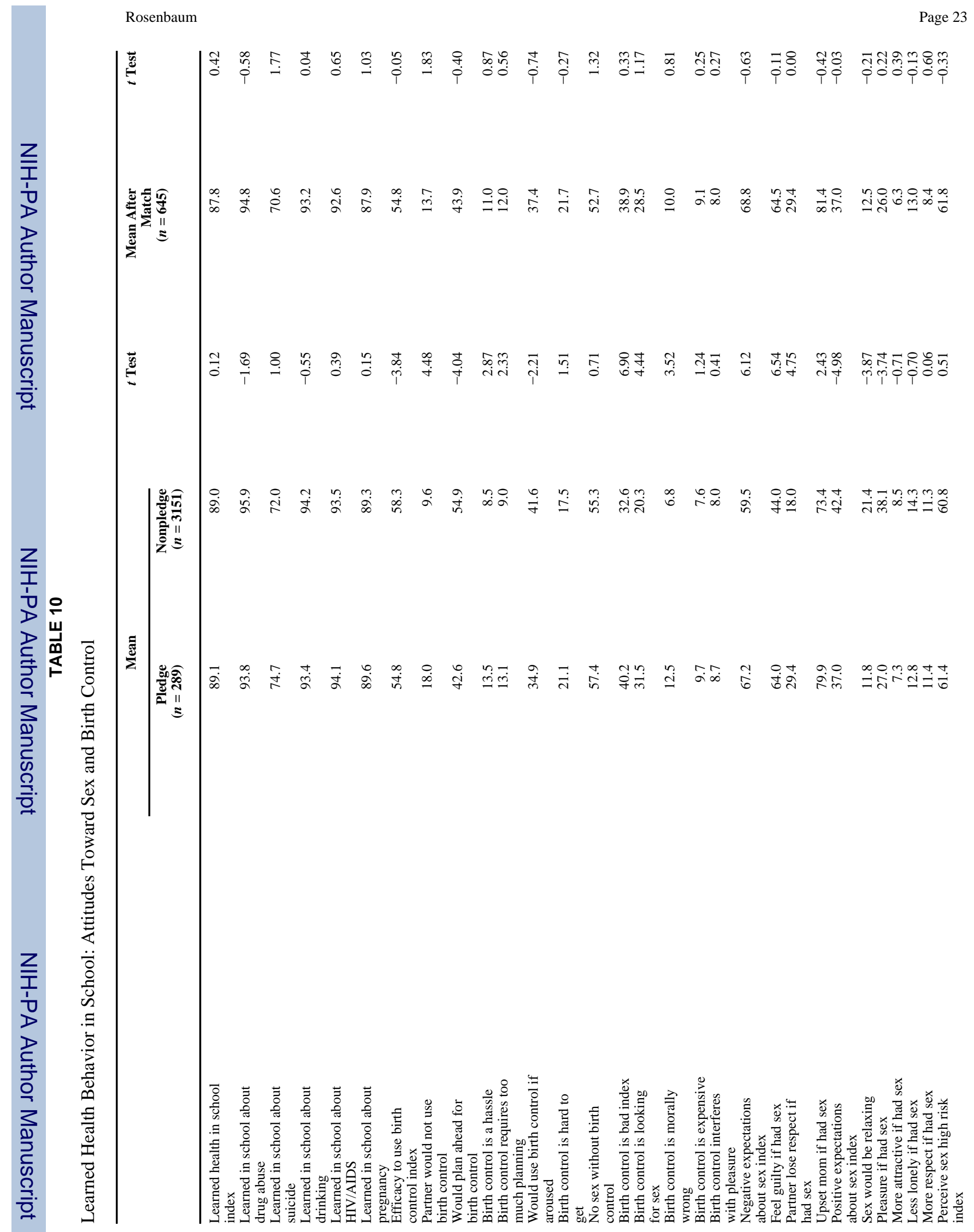

Pediatrics. Author manuscript; available in PMC 2009 October 27. 


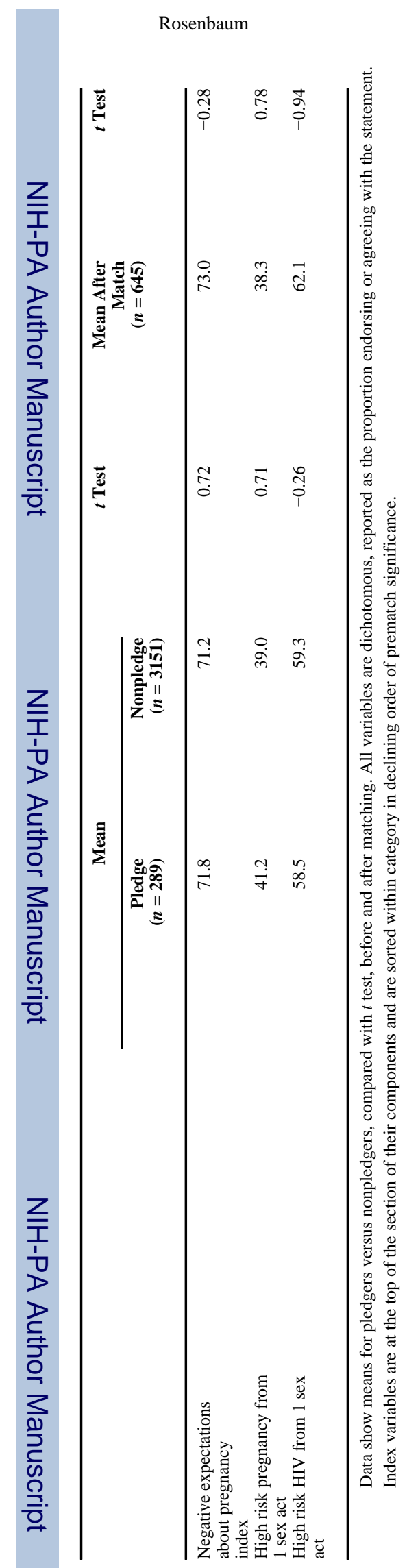

Pediatrics. Author manuscript; available in PMC 2009 October 27. 